\title{
Estágio em posto de saúde: prática e reflexão
}

\author{
Maria Lucia Boarini \\ Protessora do Departamento \\ de Psicologia da UEM
}

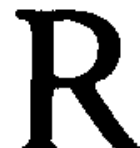

elatar uma experiência que ordene os fatos numa certa ordem lógica-cronológica não é uma tarefa difícil. No entanto, para captar a síntese das relaçōes que se estabelecem no seu interior é necessário um certo esforço de reflexão. Esforço que exige um parâmetro teórico que possibilite ir além do objeto de análise, para a abarcar as relaçōes externas que determinam a própria forma de ser do objeto.

Ao registrar essa experiência de Estágio em Psicologia do Trabalho, em um Posto de Saúde Comunitário (1), nosso estorço vai no sentido de superar a forma estritamente descritiva. Só para efeito de exposição, dividiremos o trabalho em duas partes. $\mathrm{Na}$ primeira permanece, ainda, a forma descritiva para facilitar a compreensão do leitor e, na segunda, pretendemos fazer uma avaliação crítica sobre a experiência, para que produza subsídios tanto para o curso de formação de psicólogos quanto para que (re)-oriente a nossa própria experiência.

\section{A prática}

Este trabalho em Posto de Saúde Comunitário vem se desenvolvendo há três anos consecutivos, a nível de estágio curricular, por grupos de acadêmicos sob a supervisão de professores da Universidade Estadual de Maringá. Anualmente o grupo de alunos que varia entre 3 e 4 elementos, se renova, ou seja, o grupo que já cumpriu as horas de estágio obrigatórias cede lugar a um novo grupo de alunos que estará cumprindo a mesma exigência. O Estágio no Posto é feito na área de Psicologia Clínica e Trabalho e supervisionado por dois professores

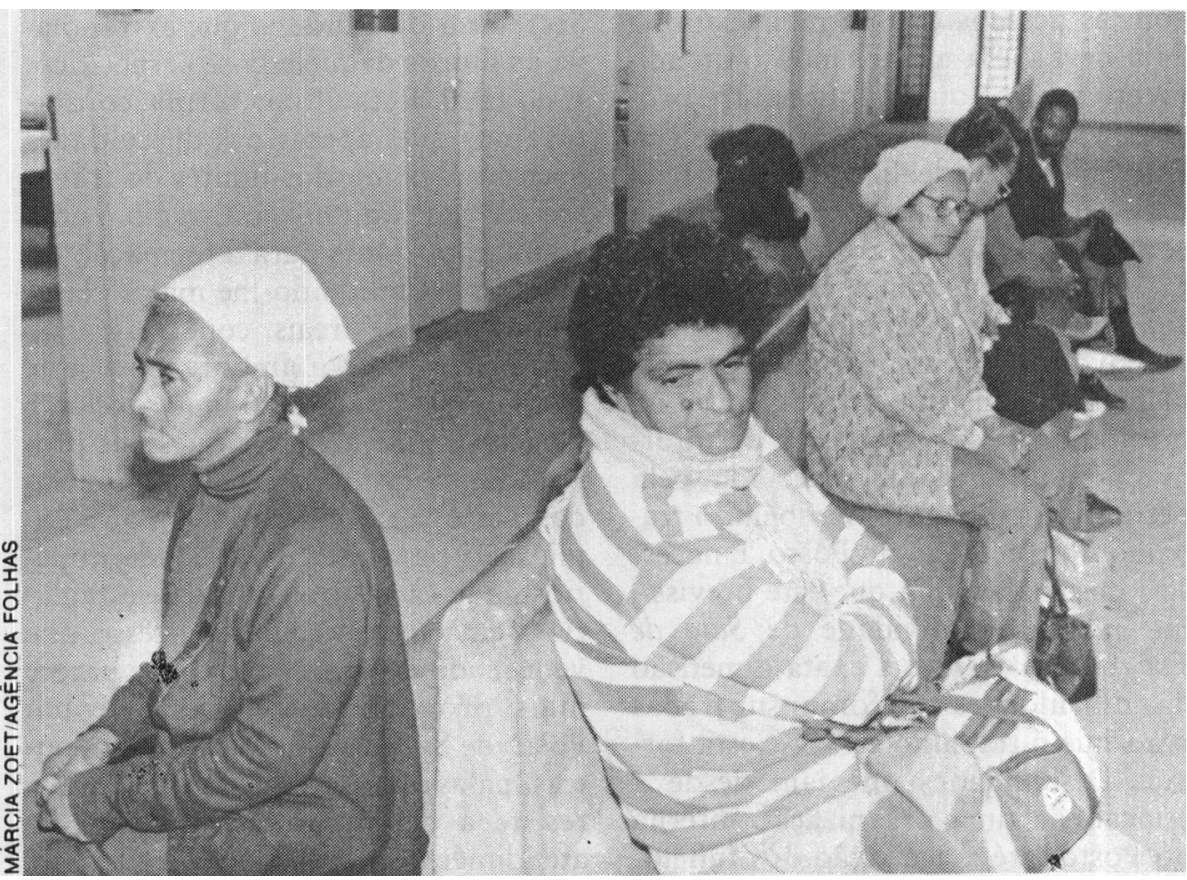

das respectivas áreas, que se reúnem, semanalmente, para discussão das atividades em desenvolvimento.

O primeiro trabalho de estágio se iniciou em agosto de 1984. A queixa principal da supervisora-enfermeira deste Posto, que o visita em alguns dias da semana, era quanto à baixa freqüência à instituiçào. Atribuía-se este fato ao alto nível sócio-econômjco da comunidade local, quando, na verdade, após diagnósticos, constatou-se, nesse bairro, um verdadeiro cinturão de misćria, onde adultos e crianças vivem em péssimas condições de saúde e de desinformação sobre serviços sociais. Partindo destes dados, fez-se un trabalho de divulgação sob a forma de uma cartilha que continha informaçōes sobre os serviços oferecidos pelo Posto. Paralela- mente a este trabalho, desenvolviamse treinamentos dos funcionários, sendo que um deles tinha por objetivo instrumentalizar os atendentes da instituição, para coordenar um grupo de gestantes. Neste primeiro aho, abriram-se horários para atendimento a nivel de terapia individual. As pessoas que procuraram este serviço (2),com exceção de duas, se limitaram a um único encontro para dizer de seus problemas, e nunca mais compareceram.

Este grupo de Estágio encerrou suas atividades no início de julho de 85 e um novo grupo retomou as atividades em agosto deste mesmo ano. Apesar do pouco sucesso que o grupo anterior tinha obtido $\mathrm{em}$ termos de atendimento individual, este $2^{\circ}$ grupo de alunos via como neçessidade bási- 
ca, para sua formação, $o$ atendimento terapêutico individual e para tanto estabeleceu horários de atendimento, caso houvesse interesse por parte da comunidade. $O$ número reduzido de casos só fez repetir o fracasso da experiência anterior. Apenas quatro atendimentos durante o ano, sendo que uma das pessoas compareceu apenas a uma sessão e a cliente que permaneceu mais tempo participou de quatro sessōes e nunca mais voltou.

Tentou-se, também, organizar um grupo de gestantes, mas a intençào não se concretizou por falta de pessoas interessadas. Por nossa sugestão, iniciou-se um trabalho de grupo com as pessoas que permaneciam na Sala de Espera aguardando o atendimento médico ou qualquer outro programa que o Posto viesse a oferecer. Este trabalho, idealizado a partir da experiência de Larrabure (3), tinha como objetivo, além de tornar a espera menos angustiante, criar nas pessoas o hábito de freqüentar o local, desenvolver discussöes sobre os problemas comuns que as afligiam e, na medida do possível, sanar a desinformação sobre saúde detectada pela pesquisa, divulgando, também, o trabalho do psicólogo no Posto. É necessário assinalar,aqui, que este brevíssimo relato da atividade de Sala de Espera não oferece a exata dimensão das dificuldades que foram superadas para que o trabalho tomasse esta forma. Dificuldades que iam desde a criação de uma organização interna do Posto, até a aceitação dos funcionários é dos próprios estagiários. Apoiados em uma formação, já histórica, que Psicologia é Clínica desenvolvida a nível individual, muitas dificuldades foram encontradas desde a linguagem adequada até a própria aceitação do trabalho. Este grupo encerra seu Estágio em julho de 1986 e, $\mathrm{cm}$ agosto do mesmo ano, um $3^{\circ} \mathrm{gru}-$ po inicia seu trabalho. Este grupo, nào fugindo à regra, tinha como proposta o atendimento individual, $\mathrm{cm}$ bora conhecesse o insucesso dos grupos anteriores. Três casos foram atendidos durante o ano, sendo grande o número de desistentes. Quanto à Sala de Espera, pelo tempo em que esta atividade esteve ausente, considerando que durante as férias nada foi desenvolvido a nível de Estágio, já havia perdido muito do clima, da dinâmica, da receptividade para estas reuniōes, além do fato de que este novo grupo necessitava de um tempo para aceitar este tipo de atividade como sendo uma das possiveis atividades do psicólogo. Foi desenvolvido, também, um estudo dos diagnósticos médicos a nível de psicossomatizaçāo quando se constatou uma alta incidencia de queixas, onde os componentes social e psicossomático se destacavam. A proposta era discutir com o médico a possibilidade de se fazer atendimentos dos casos que caracterizavam somatização. Mas por questōes internas do grupo de estagiárias, este trabalho não teve prosseguimento. Foi desenvolvido, ainda, um trabalho de Descrição e Análise de Cargos em toda a Secretaria da Saúde, o que extrapolava os muros daquele Posto específico. E no final desta última turma, constatávamos que, apesar das dificuldades encontradas, ou dos limites do trabalho em seu conjunto, o Estágio é uma etapa importante para a formação do aluno, possibilitando-lhe maior clareza das questões reais, concretas.

Entretanto, a importância que atribuímos ao estágio não exclui e nem responde algumas questōes provocadas pelas dificuldades vicenciadas neste período, como: Qual a explicação para esta necessidade imperiosa que cada novo grupo de estagiários tem em reverter o processo que vem sendo encaminhado e que parece mais próximo da realidade de um Posto de Saúde Comunitário? Em outras palavras, por que o acadêmico resiste à determinadas práticas de atendimento grupal e privilegia a terapia individual, quando já foi comprovada sua inviabilidade neste tipo de instituição? Será que as dificuldades que se apresentam ao levar uma proposta de Estágio como esta são disfunçōes que podem ser saneadas no interior da própria experiência ou têm sua determinação fora da experiência $\mathrm{e}$, portanto, fora do controle dos sujeitos que nela atuam?

É a busca de respostas a estas questōes que nos conduzirá a $2^{2}$ parte deste trabalho.

\section{AS REFLEXÕES}

$O$ refletir desta prática exige a discussão de alguns pontos para nos aproximar da compreensão do que ocorre durante o Estágio de Psicologia em Posto de Saúde Comunitário. Inicialmente é necessário ter claro, como primeiro ponto, qual é a proposta do Estágio Curricular em Psicologia. Como segundo ponto: de que maneira tem-se configurado a formação destes graduados numa sociedade de classes e,derivada desta questão, qual tem sido a expectativa que os Cursos de Psicologia vêm gerando em seus alunos. Acreditamos que a visualização destes pontos nos permitirá compreender o significado, as dificuldades, as limitações e as possibilidades do estágio em Posto de Saúde Comunitário, que se constituirá no último ponto a ser abordado.

A proposta do estágio curricular e a formação do psicólogo:

De acordo com o Parecer $n^{\circ}$ $403 / 62$, que fundamentou a Resolução que fixa o Currículo Mínimo e a duração do Curso de Psicologia, temse que o trabalho do psicológo é impossível sem o devido treinamento prático de pelo menos 500 hs de atividade, em forma de Estágio que deve se desenvolver em situaçōes reais.

Ressalvado que o Posto de Saúde Comunitário é um local que apresenta situaçōes reais de vida para o exercício de educação e reeducação do psicólogo, passemos ao segundo ponto: a formação do psicólogo.

Discutir a formação do psicológo exige, de imediato, o resgate de alguns importantes estudos sobre esta matéria. Assim, Mello (4), assinalan. do o prestígio atribuído pelos Cursos de Psicologia à orientação clínica diz:"... o psicólogo é acima de tudo, um profissional liberal, assim o dizem a legislação, seu curso univestiário, seus professores. Esse o conteúdo essencial das suas aspiraçōes e, posteriormente, das suas realizaçôes. Para tanto, toma de empréstimo o modelo típico do profissional liberal, o médico, e molda a sua imagem à semelhança dele". E apontando os problemas decorrentes, a manter-se a atual orientação dos Cursos de Psicologia diz: "...estaremos formando profissionais nāo apenas desajustados às formas mais modernas de aplicação da Psicologia, mas sobrerudo, decepcionados pelas reais condiçōes de exercício profissonal que irão encontrar" (5).

Gil (6), por sua vez, refletindo sobre ideologia, aponta que paralelamente às dificuldades que os psicólogos encontram na área clínica, as Entidades de Classe e os Conselhos de Psicologia voltam-se preferencialmente para a defesa dessas atividades. 
Carvalho (1984) (7) confirma de alguma forma tais afirmaçōes. assinalando que, de 367 psicólogos entrevistados, $66 \%$ informam que sua melhor formação escolar passou pela área de clínica, reforçando, assim, a preferência por esse tipo de atividade. Essa escolha, por outro lado, é entendida como sinônimo de trabalho em consultório particular, (8) mesmo que seja exercida em Postos ou Centros Comunitários, e, mesmo que nessas instituiçōes receba outro nome como o de Psicologia Social. Enfim, mantémse a prática e troca-se de nome de acordo com a natureza da agência que presta o serviço(9). Razão pela qual, talvez, nessas observaçōes se encontre a ponta do "iceberg" para entender por que, em pesquisa realizada por Carvalho (1984), os acadêmicos significativamente apontam a formação teórica como "positiva" e a formação prática como "negativa". Problema sério que não só revela uma leitura universitária fragmentada e estática da realidade, como revela uma dicotomia idealista na apreensão da realidade. Problema sério porque o acadêmico não se dá conta que a teoria deve responder às questőes reais; c, quando a sua vivência prática não encontra respaldo teórico explicativo, alguma coisa no currículo escolar anda em falsete. A questão, de fato, não se resume em "teoria positiva" e "prática negativa". A questão não é de maior ou de menor valor para uma ou outra coisa, mas de se perguntar por que a teoria não dá conta explicativa das vivências ou da prática em determinadas instituiçōes. A pergunta E: a preparação teórica do acadêmico é adequada às experiências reais de uma sociedade de classes?

Convém lembrar que a Universidade, em geral, apregoa e enfatiza os princípios de Liberdade, Igualdade e Fraternidade, quando; de fato, estes princípios nunca deixaram de ser somente princípios e nada mais. Estes princípios atuam na formação acadêmica no sentido de mobilizar atividades para transformar qualquer situação, qualquer conjuntura, em realidades localizadas de absoluta igualização sem que seja necessário tocar na estrutura que fundamenta a sociedade de classes. Os limites dos princípios da Igualdade e Liberdade - regulados pelo próprio modo de produzir a vida que divide por "natureza" a sociedade capitalista em classes - não são discutidos em sua verdadeira exeqüibilidade. E, por isso mesmo, se "romantiza" o processo de transformação a nível de grupos isolados ou em situaçōes específicas, demonstrandose que as coordenadas que regem o sistema social mais amplo são desconhecidas em sua totalidade.

Estes pontos, discutidos acima, podem não estar claros para os acadêmicos, mas, sem dúvida, são por eles vivenciados e revelados quando, durante o estágio ou até mesmo na sua atuação profissional, os "modelos" de atuaçã̃o escolhidos não dão certo. Ou quando se queixam que a Universidade não os preparou adequadamente; ou, ainda, quando dicotomizam sua formação em "teórica boa" e "prática ruim", reivindicando mais técnicas para resolver dificuldades "inesperadas", porquanto a desigualdade real não fazia parte nem da sua formação nem do seu plano de vida e/ou trabalho. $O$ acadêmico não se dá conta que a sua expectativa foi gerada a partir de sua formação e é voltada para uma classe que não apenas tem condições de ter seus problemas emocionais como prioridade, mas tem condições materiais para compreendê-los e resolvê-los. A expectativa de fazer clínica em Centros Comunitários enfrentra-se com uma classe que nem sequer reconhece a psicologia por ter necessidades materiais tão fortes que sobrepujam as emocionais e/ou as elaboraçōes psíquicas, desvalorizando, assim, este tipo de intervenção por questōes de sobrevivência imediata. (Daí porque os serviços médicos, dentários, os programas de distribuição de remédios ou alimentos são reconhecidos e procurados). Assim sendo, esta discussão sobre a formação do psicólogo, ainda que muito breve, já nos possibilita entrar no terceiro ponto deste trabalho.

\section{Encaminhando discussöes}

A população que procura o Posto de Saúde - constituída prioritariamente da classe desprivilegiada busca, por excelência, atendimento médico. Em três anos de nossa experiência efetivaram-se anualmente, em média, 4200 consultas médicas no Posto de Saúde de Mandacarú e 4 atendimentos a nível de terapia individual (entendida esta como a situação em que o cliente durante algum tempo permanece interagindo com o psicólogo na busca de identificação e elaboração de problemas emocionais). Esta realidade obriga que tanto a formaçāo do psicólogo quanto a função do psicólogo em uma sociedade de classes seja repensada, reavaliada. Esta realidade exige uma análise aprofundada que ultrapassa este texto, o qual, de fato, só pretende encaminhar discussōes preliminares. Dentre as questōes preliminares pretendemos abordar: 1) a ansiedade do acadêmico em propor "trabalhos novos" que não dão continuidade a programas vividos por seus colegas, em momentos anteriores à sua presença no Posto; 2) a exigência de investir em rerapia individual como condição do universitário sentir-se profissionalmente realizado.

Em nossa experiência sempre observamos resistência, por parte dos grupos novos, para continuidade dos trabalhos já iniciados. Embora lhes seja assinalada a necessidade e importância da continuidade, esta questão não é devidamente privilegiada. Podese entender que este fato ocorre porque, após as férias, os novos estagiários encontram o trabalho anterior semi-apagado, semi-esquecido. Decididamente retomar algo que ainda não tem forma definida não é fácil, mas isto não justifica o abandono, negação ou rejeição do conhecimento e/ou da prática, relativo a intervenções anteriores, posto que o reconhecimento do que já foi feito é uma exigência mínima de qualquer trabalho que tenha por intençöes ser progressivamente articulado. Mas, então, como se explica a exigência de descontinuidade que os acadêmicos trazem no início de cada Estágio? Parece-nos que tal descontinuidade se situa, de forma próxima, à formação escolar que tendo por modelo o profissional liberal joga, em determinado momento, o estagiário para um universo que não é o de consultório particular, no qual o acadêmico não sabe se movimentar. Ao mesmo tempo o psicólogo sofre do impacto - mesmo oferecendo serviços gratuitos considerados relevantes - de não ser procurado na mesma intensidade que seus colegas de outra área, desequilibrando a imagem (à semelhança do médico) que fez de si mesmo. $O$ aluno preparado para fazer clínica sofre a experiência de classe social, sem reconhecê-la como tal, à medida que mes- 
mo quando tem pacientes, estes se evadem ("sem se saber por que") antes de o profissional ter feito seu diagnóstico. As impossibilidades reais de clínica em Postos de Saúde - rejeitadas a priori pelos alunos - parecem ser os fatores mais próximos das exigências de ruptura com trabalhos já iniciados por turmas anteriores. Por sua vez, a opção por outros trabathos - feitos por grupos anteriores que não privilegiam a clínica nada mais é do que uma "aceitação incômoda" que a realidade rebelde do Posto Comunitário impōe aos psicólogos... O esforço que cada turma de estagiários faz para subverter o trabalho dos que lhes precederam termina por "concessōes" ou por "submissôes" a outras atividades que não trazem nenhum respaldo teórico curricular. A história do Posto, a cada novo grupo, é questionada por sensocomum, por ansiedade, por exigências de trabalhos que buscam respostas a curto prazo para um tipo de cliente que aumenta numericamente à medida que se reproduz o capitalismo. Aumento vertiginoso que faz com que o número de instituiçōes comunitárias também aumente, aumentando este campo real de estágio para a Psicologia.

Nesta sintonia da descontinuidade, só uma prática se mantém: a terapia individual. Contudo a insistência em mantê-la viva em condiçōes inadequadas para sua existên. cia é condená-la à extinção. Insistir em fazer terapia individual, trabaIhar o emocional, elaborar conteúdos, em uma população que em sua maioria (isto na melhor das hipóteses) não tem suas necessidades básicas atendidas, é não ter a devida dimensão das necessidades do homem e das exigências para que a terapia psicológica chegue a bom termo, condenando ao esquecimento tão importante contribuição científica da Psicologia. Isto não significa que o homem privado de suas necessidades básicas não tenha problemas emocionais que mereçam atendimento terapêutico psicológico. Pelo contrário, é exatamente por entender o ser humano como uma unidade indivisível, que vive em privação dos elementos básicos para a sua sobrevivência, revestido de privaçöes e incompreensões, que ele precisaria de atendimento psicológico. Contudo, quer queiramos ou

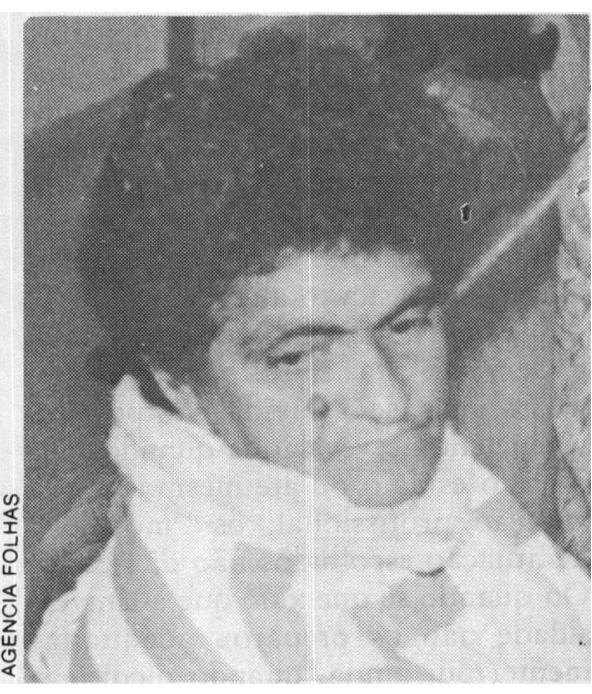

não, existe uma ordem em termos de atendimento às necessidades básicas que, com sabedoria, o refrão popular expressa: "saco vazio nāo para em pé". Nessas condiçöes o homem não tem elementos necessários para discriminar, identificar seus conflitos emocionais. Geralmente a única dificuldade que se dá conta é o imediatamente visível: o orgânico. A prova contundente desta afirmação é a alta freqüência aos Postos de Saúde nos horários médicos ou de programas de distribuição de alimentos, que aliviam a dor ou enchem o estômago. Não são necessários planos ou reflexōes a respeito para garantir a demanda; a freqüência é garantida apenas pela presença do médico ou pela distribuição do alimento.

São estes fatos, são estas dificuldades reais que devem ser cotejadas, analisadas sob o pressuposto materialista de que "são as condiçöes materiais que determinam a consciência"(10). Se o homem não tem condiçôes de atender suas necessidades básicas (alimento, moradia, saúde...) novas exigências de vida nem aparecerão nem poderão ser criadas. As condiçōes reais de privação exigem a busca do imediato, $e$ este imediato se revela apenas na necessidade de manter-se em pé, apenas organicamente vivo.

Sem ter clareza sobre satisfação de necessidades (imediatas) pertinentes a uma sociedade de classes, o aluno pode gerar a falsa idéia que doutrinas ou teorias psicológicas precisam de reformulações porque foram geradas ou criadas pela classe dominante. Antes de condenar a psicologia ao quadro da classe dominante, ou, antes de condenar os que a procuram como burgueses, seria interessante perguntat se, dadas condiçōes iguais para os homens terem necessidades semelhantes, a demanda pela clínica em Postos de Saúde não seria diferente, ou ainda, seria o caso de perguntar se o problema da falta de demanda por uma classe social é conseqüência das teorias psicológicas ou é anterior à questão da própria psicologia.

É a realidade social que produz homens diferentes: subnutridos, enfermiços, sem trabalho e que não identificam na terapia psicológica a sua necessidade mais urgente. São as relaçōes sociais estabelecidas que confirmam as condiçōes materiais básicas insuficientes para a vida. São as próprias relaçōes sociais de trabalho estabelecidas que concretizam a desigualdade de necessidades e a falta de liberdade para a aquisição de exigências humanas de nível superior.

Diante dessas consideraçōes é de se questionar até que ponto o psicológo, que faz da terapia individual a sua preferência irrestrita, desconsiderando as condiçōes materiais do indivíduo, está comprometido com uma visão liberal de afirmação da igualdade de todos e da liberdade de cada um para procurar o melhor para si. $E$ de se questionar até quanto o psicólogo percebe que suas práticas pretendidas como verdadeiras e válidas têm seus limites concretos na existência da pobreza.

1 - O Posto de Saúde Comunitário de Mandacarú localiza-se no bairro do Mandacarú, no município de Maringá é faz parte da rede municipal de Posros de Saúde, mantidos pela Prefeitura local.

2 - Em um total, neste ano, de 34 pessoas

3 - LARRABURE, S.A. - Grupos de Espera em Instituifāo. Sāo Paulo, PUC, 1982. (Tese Mestrado).

4- MELlo, Leser de. Psicologia e Profissāo em Sāo Paulo. Sào Pạulo, Ática, 1975. p. 77

5 - Id. ibid.

6 - GIL, A.C.O. O Psicólogo e sua Ídeologia. Tese de Doutorado (1982) In: Psicologia, Ciência e Profissäo, ano 5, 1:1217, 1985.

7 - CarvalHo, A.M.A. Atuaçāo Psicológica. In: Psicologia, Ciência e Profissäo, ano 4, 2:6-9, 1984.

8 - Vide Leser de Mello, op. cit.

9 - Vide Carvalho, op. cit.

10-mARX, K; ENGELS, F. A Ideologia Alemã São Paulo, Hucitec, 1986. 